\title{
The Novel C5aR Antagonist DF3016A Protects Neurons Against Ischemic Neuroinflammatory Injury
}

\author{
Laura Brandolini ${ }^{1}$ - Marta Grannonico ${ }^{2}$ - Gianluca Bianchini ${ }^{1}$ - Alessia Colanardi ${ }^{3}$. Pierluigi Sebastiani ${ }^{3}$. \\ Antonella Paladini ${ }^{2} \cdot$ Alba Piroli $^{2} \cdot$ Marcello Allegretti $^{1}$ - Giustino Varrassi ${ }^{4} \cdot$ Silvia Di Loreto $^{3}$ (ID
}

Received: 4 December 2018 / Revised: 14 March 2019 / Accepted: 15 March 2019 / Published online: 5 April 2019

(C) The Author(s) 2019, corrected publication 2019

\begin{abstract}
The central nervous system (CNS) constitutively expresses complement (C) membrane receptors and complement proteins, including the component $\mathrm{C} 5 \mathrm{a}$. This is a crucial terminal effector of the $\mathrm{C}$ cascade, mostly involved in pain and neuroinflammatory conditions. Aberrant activation of $\mathrm{C} 5 \mathrm{a}$ protein and its receptor $\mathrm{C} 5 \mathrm{aR}$ has been reported to play a critical role in neurodegenerative diseases, with important clinical consequences. Here we have investigated the effects of DF3016A, a novel selective C5aR antagonist, able to penetrate the blood-brain barrier (BBB), on cortical neurons exposed to oxygen-glucose deprivation-reoxygenation $(\mathrm{OGD} / \mathrm{R})$, a neuroinflammation-related process. We demonstrated that a mild ischemic insult induces an early upregulation of $\mathrm{C} 5 \mathrm{aR}$ associated with the over-production of pro-inflammatory cytokines and the over-expression of the transcriptional regulatory factor miR-181. Furthermore, we report the first experimental evidence of the effect of DF3016A, modulating complement component $\mathrm{C} 5 \mathrm{a}$, on neurons in a model of injury. Interestingly, DF3016A protects neuronal viability by restoring intracellular calcium levels, thus opposing the increase in pro-inflammatory cytokine levels and miR-181 expression. Based on our results, we suggest that DF3016A is a novel C5aR antagonist promoting protective effects against OGD/R-induced damage that could be a new therapeutic approach to controlling CNS neuroinflammatory conditions.
\end{abstract}

Keywords Neuroinflammation $\cdot$ Complement $\cdot$ C5a $\cdot$ Cortical neurons $\cdot$ Cytokines $\cdot$ Pain

\section{Introduction}

Neuroinflammation and neurodegenerative processes have been strongly related to chronic pain (Alexander et al. 2008; Varrassi et al. 2015). They may be consequent to the activation of complement in the central nervous system (CNS) (Van Beek et al. 2003). More recently, the importance of neurodegenerative processes has been related to concomitant pathological conditions connected to pain such as paraneoplastic neuropathies, rheumatic, and joint diseases (Fusco et al.

Laura Brandolini and Marta Grannonico contributed equally to this work.

Silvia Di Loreto

silvia.diloreto@cnr.it

Dompé Farmaceutici SpA, Via Campo di Pile, L'Aquila, Italy

2 Department of MESVA, University of L'Aquila, L'Aquila, Italy

3 Institute of Translational Pharmacology (IFT) - National Council of Research (CNR), L'Aquila, Italy

4 Paolo Procacci Foundation, Via Tacito 7, 00193 Rome, Italy
2017; Zis et al. 2017; Zis et al. 2017a). Despite being immunologically separate from the circulating plasma, and in the absence of blood-brain barrier (BBB) damage, cells of the CNS express many components of immunity including all complement (C) factors (Woodruff et al. 2010; O'Barr et al. 2001). The $C$ system, composed of a large number of serum proteins and membrane-bound receptors, among others, protects from infection through innate and adaptive immune mechanisms (Carroll 1998; Song et al. 2000). In the CNS, complement component 5a (C5a) and its cell membrane receptor $(\mathrm{C} 5 \mathrm{aR})$ are constitutively expressed not only in astrocytes and microglia (Müller-Ladner et al. 1996) but also in neurons (Davoust et al. 1999; O'Barr et al. 2001; Pavlovski et al. 2012). The $C$ cascade pathway is involved in pain mechanisms (Gasque et al. 1997), and the inappropriate activation of complement produces a local inflammatory reaction. Much evidence indicates that $\mathrm{C} 5 \mathrm{a}$ and $\mathrm{C} 5 \mathrm{aR}$ play a critical role in neurodegenerative diseases (Yanamadala and Friedlander 2010; Zhou et al. 2009; Quadros and Cunha 2016; Barnum 2002; Farkas et al. 2003), and the C5a has a number of effects on neurons in vitro (Mukherjee and Pasinetti 2001; Farkas 
et al. 1998; Pavlovski et al. 2012). For more than 30 years, researchers have actively investigated the role of the immune system (IS) and specifically, C proteins, in human neurodegenerative diseases and mouse models (Alexander et al. 2008). C production in the CNS not only protects from invading pathogens but also may have a regulatory role in neuronal processes (Farkas et al. 2012; Farkas et al. 2008). However, there is compelling evidence that it can exert a dual role in the CNS, depending on the pathophysiological context (van Beek et al. 2003). Stevens et al. (2007) reported a C involvement during brain development in physiological homeostasis and pruning of unwanted synapses, suggesting that the aberrant reactivation of complement-mediated synapse elimination may take place in neurodegenerative conditions (Mukherjee and Pasinetti 2000). After ischemic stroke, the progression of brain injury also involves complement mediated changes (Alawieh et al. 2015).

Acute ischemic stroke is responsible for almost $90 \%$ of neuronal injuries following deprivation of oxygen and nutrients. During the ischemic cerebrovascular events, there are two zones: the "ischemic core" and the "ischemic penumbra." Focal ischemic stroke induces neuronal death in the "core" and molecular and cellular alterations in the "penumbra," changes that are temporal/spatial-dependent. The term ischemic penumbra is generally used to define the tissue surrounding the severe ischemic core where blood flow is reduced to cause hypoxia, but not sufficient to result in irreversible failure of energy metabolism and cellular necrosis (Astrup et al. 1981). Ischemic penumbra is a diagnostic and biochemical target for brain plasticity, neuroprotection, and neurorepair. Moreover, a sublethal preconditioning injury strongly increases the neuronal resistance to subsequent injury by stimulating protective processes (Badaut et al. 2005; Kawahara et al. 2004; Narayanan and Perez-Pinzon 2017).

Oxygen-glucose deprivation/reoxygenation (OGD/R) procedure provides an in vitro model of neuroinflammationrelated processes (Goldberg and Choi 1993) that are crucial elements in the injury onset and progression. To better understand the relevance of $\mathrm{C} 5 \mathrm{a}$ modulation in this context, we ran a medicinal chemistry program (Moriconi et al. 2014) that led to the identification of DF3016A, a novel potent and selective $\mathrm{C} 5 \mathrm{aR}$ inhibitor with tailored pharmacological properties. Herein, we report and evaluate the in vitro characterization and the experimental effects of DF3016A, on primary rat cortical neurons exposed to sublethal OGD/R.

\section{Materials and Methods}

\section{Cell Isolation and Culture}

Polymorphonuclear cells (PMNs) were obtained from buffy coats of heparinized peripheral blood from adult healthy volunteers, as previously described (Bertini et al. 2004). Ethical clearance was obtained by local ethical review committees and conformed to Italian regulations. PMNs were separated by dextran sedimentation followed by hypotonic lysis of contaminating red blood cells as previously described (Bertini et al. 2004). Cell viability, as measured by trypan blue dye exclusion, was greater than $98 \%$.

Murine and rat PMNs were isolated from peritoneal cavities injected with $1.5 \mathrm{ml}$ of $3 \%$ thioglycolate in saline to male Balb/c mice (20-25 g and 7-9 weeks of age, provided by Charles River, Calco, Italy) or with $10 \mathrm{ml}$ of $1.5 \mathrm{ml}$ of $3 \%$ thioglycolate in saline to SD rat (370-450 g and 3-4 months of age provided by Charles River, UK). Four hours after injection, the animals were sacrificed by decapitation and peritoneal cavities were washed with saline. PMNs were recovered and centrifuged at $600 \times g$ for $10 \mathrm{~min}$. The pellet was resuspended in Hank's Balanced Salt Solution (HBSS); then the cells were counted using Türk's solution and diluted at $3 \times$ $10^{6} \mathrm{cells} / \mathrm{ml}$.

\section{Migration Assay}

Migration of human, rat, and mouse PMNs was evaluated using a 48-well micro-chemotaxis chamber, as previously described (Bertini et al. 2004). Briefly, $25 \mu$ of control medium HBSS for human and rodent PMNs, or chemoattractant solution $10 \mathrm{nM}$ chemokine (CXC motif) ligand 1 (CXCL1), $1 \mathrm{nM}$ CXCL8 or CXCL1/KC for rodent PMNs, $10 \mathrm{nM} \mathrm{C5a}$ or $10 \mathrm{nM} \mathrm{mC5}$ a or rC5a for rodent PMNs, $10 \mathrm{nM}$ CXCL12, and $10 \mathrm{nM} \mathrm{n}$-formylmethionyl-leucyl-phenylalanine (fMLP) were seeded in the lower compartment of the chemotaxis chamber. Fifty microliters of cell suspension $\left(1.5 \times 10^{6} / \mathrm{ml}\right.$ for human PMNs, $3.0 \times 10^{6} / \mathrm{ml}$ for rat and mouse PMNs) pre-incubated at $37^{\circ} \mathrm{C}$ for $15 \mathrm{~min}$ in the presence or absence of different concentrations of DF3016A or vehicle was seeded in the upper compartment. The chamber was incubated at $37^{\circ} \mathrm{C}$ in air with $5 \% \mathrm{CO}_{2}$ for $45 \mathrm{~min}$. At the end of incubation, filters containing migrated cells were removed, fixed, and stained with Diff-Quik, and five oil immersion fields at high magnification $(\times 100$; Zeiss microscope $)$ were counted after sample coding.

\section{Peritoneal Murine Macrophage Preparation and Lipopolysaccharide-Induced Prostaglandin E2 Production}

Peritoneal exudate cells were collected from peritoneal washings of male mice Balb/c mice (20-25 g and 7-9 weeks of age, provided by Charles River, Calco, Italy), 5 days after i.p. injection of $3 \%$ thioglycollate in saline $(1.5 \mathrm{ml}$ per mouse), as previously reported (Mascagni et al. 2000). Cells were placed at $1 \times 10^{6} \mathrm{ml}^{-1}$ in 96-well plates and non-adherent cells removed by gentle washing $2 \mathrm{~h}$ later. DF3016A was then added 
to adherent macrophages 20 min before adding lipopolysaccharide (LPS) $\left(1 \mu \mathrm{g} \mathrm{ml}^{-1}\right)$. Control cells received vehicle at the appropriate dilution. Total prostaglandin E2 $\left(\mathrm{PGE}_{2}\right)$ production was determined in the supernatant $24 \mathrm{~h}$ after LPS stimulation. $\mathrm{PGE}_{2}$ levels were measured by Enzyme Immunoassay (EIA) Kit (sensitivity 2.5 pg per well).

\section{In Vitro Selectivity}

DF3016A was tested in the SafetyScreen44 Panel performed at Eurofins Cerep SA (France) by radio ligand binding assays to assess the off-target activities towards a panel of GPCRs, enzymes, ion channels, transporters, and nuclear receptors. All selected targets are recommended by four major pharmaceutical companies (Bowes et al. 2012). The compound was tested at a single concentration of $10 \mu \mathrm{M}$ in triplicate.

DF3016A was dissolved in dimethyl sulfoxide (DMSO) to achieve $10 \mathrm{mM}$ stock solution that was diluted with water/ HBSS to a final concentration of $10 \mu \mathrm{M}$. Cell membrane homogenates $(48 \mu \mathrm{g}$ protein) were incubated for $60 \mathrm{~min}$ at $22{ }^{\circ} \mathrm{C}$ with the respective reference compound in the absence or presence of the test compound in a buffer containing $50 \mathrm{mM}$ Tris- $\mathrm{HCl}(\mathrm{pH} \mathrm{7.4}), 2 \mathrm{mM} \mathrm{MgCl}$, and $1 \mathrm{mM}$ ethylene-diamine-tetra-acetic acid (EDTA). After incubation, the samples were filtered rapidly under vacuum through glass fiber filters (GF/B, Packard Instruments, Meriden, CT, USA) presoaked with $0.3 \%$ polyethyleneimine (PEI), and rinsed several times with ice-cold $50 \mathrm{mM}$ Tris- $\mathrm{HCl}$ using a 96sample cell harvester (Unifilter, Packard Instruments). The filters were dried, then counted for radioactivity in a scintillation counter (Topcount, Packard Instruments) using a scintillation cocktail (Microscint-O, Packard Instruments).

\section{Brain Penetration in the Rat}

DF3016A was studied in male Sprague Dawley rats $(n=3)$ to investigate the $\mathrm{BBB}$ penetration after oral administration. SD rats (370-450 $\mathrm{g}$ and 3-4 months of age at the time of testing) were purchased from Charles River, UK. All animals were housed in groups of three per room under controlled conditions of temperature $\left(19\right.$ to $21^{\circ} \mathrm{C}$ ) and humidity (50\%), and maintained on a 12-h light/dark cycle (lights on at 7 and lights off at 19 including a 30-min dawn/dusk lights increasing/ dimming period, respectively). Animals had free access to rat chow pellets CRM $(\mathrm{P})$ and water except during the experimental procedures. All animals were weighed immediately before the test. The test drug was administered orally at $30 \mathrm{mg} / \mathrm{kg}$ using saline solution $(0.9 \% \mathrm{NaCl})$ as vehicle. The animals were sacrificed at $T_{\max }(2 \mathrm{~h}$ postdose $)$ with sodium pentobarbital administered intraperitoneally. Cardiac blood samples, $0.6 \mathrm{ml}$, were obtained and placed in EDTA-coated tubes. The tubes were spun at $13,000 \mathrm{rpm}$ for $4 \mathrm{~min}$ and $100 \mu \mathrm{l}$ of supernatant taken and immediately stored at $-80{ }^{\circ} \mathrm{C}$ prior to analysis. Plasma samples were analyzed by liquid chromatography-mass spectrometry (LC-MS/MS) following extraction by protein precipitation with internal standard in acetonitrile, and levels of parent measured against an extracted calibration curve of plasma samples spiked with test compound. The whole brain was harvested then placed in a plastic tube and immediately frozen at $-80^{\circ} \mathrm{C}$ until required. Brain tissue were homogenized and analyzed by LC-MS/MS following extraction by protein precipitation, and levels of parent measured against an extracted calibration curve of brain homogenate samples spiked with the test compound. Total exposure levels of the test compound in brain and plasma at $2 \mathrm{~h}$ postdose were determined.

\section{Primary Cortical Cultures}

Neuronal cultures were prepared from cortices of 17-18day-old Sprague-Dawley rat fetuses. Two pregnant rats, provided from Envigo RMS S.r.1. (Z.I. Azzida, 5733,049 S. Pietro al Natisone, Udine Italy), were euthanized by exposition to a gradually rising concentration of $\mathrm{CO}_{2}$ and then decapitated. Rat brains were isolated using standard procedures, and after the elimination of meninges, the cortical tissues were dissociated by trituration and digestion with $20 \mathrm{U} / \mathrm{ml}$ papain (Invitrogen, Karlsruhe, Germany) for $30 \mathrm{~min}$ at $37^{\circ} \mathrm{C}$. Approximately $1 \times 10^{6}$ cells in $1 \mathrm{ml} \mathrm{DMEM} / \mathrm{F} 12$ medium containing $0.2 \mathrm{mM}$ Glutamax, $1 \%$ penicillin/streptomycin (Pen/Strep), 5\% fetal bovine serum, and $5 \%$ horse serum were seeded into poly-D-lysine pretreated plates. After 4-6 h, the medium was changed with Neurobasal containing the serum-free B27 supplement (2\%), 1\% Pen/Strep, and $0.2 \mathrm{mM}$ Glutamax that selectively inhibits glial proliferation. Neurons were maintained in a humidified atmosphere $\left(5 \% \mathrm{CO}_{2} / 95 \%\right.$ air) at $37^{\circ} \mathrm{C}$ and used for experiments after 8-10 days in vitro. All experimental procedures were performed according to Italian law 116/92, authorization no. 104-2013-A.

\section{Drug Treatment}

DF3016A was dissolved in DMSO. The final concentration of DMSO in the medium was below $0.1 \%$. To characterize toxicity, primary cultures were treated for $24 \mathrm{~h}$ with different DF3016A concentrations $(10 \mathrm{nM}, 50 \mathrm{nM}, 100 \mathrm{nM}, 500 \mathrm{nM}$, $1 \mu \mathrm{M}, 5 \mu \mathrm{M}, 10 \mu \mathrm{M}, 100 \mu \mathrm{M}, 0.5 \mathrm{mM}, 1 \mathrm{mM})$, finally treated with suitable concentration, and exposed to OGD/R (1 h first, and then $3 \mathrm{~h}$ ). Control conditions underwent neither drug treatment nor OGD/R. After treatments, cultures were used for in vitro experiments. Different tests were carried out as described below. 


\section{Experimental Model}

We performed an experimental model in vitro reproducing neuroinflammation stress condition. Less than 50\% mortality was induced to mimic the damage occurred in the area surrounding the ischemic core where neurons still have capacity for recovery. Previously time-response experiments conducted for more than $1 \mathrm{~h}(2 \mathrm{~h})$ of OGD induced more than $50 \%$ mortality (data not shown). On this basis, we selected only 1-h OGD that induces about $20 \%$ mortality in primary neuronal cultures and allows resilience of alive neurons.

\section{OGD/R}

DF3016A (500 nM) was added to the cortical neurons which were exposed to $\mathrm{O}_{2}$ and glucose deprivation with glucose-free Neurobasal in Hypoxia Chamber for Cell Culture (BioSpherix) at 5\% $\mathrm{CO}_{2}$ atmosphere- $85 \% \mathrm{~N}_{2} . \mathrm{O}_{2}$ concentration was monitored by using a ProOx sensor controller, and the $0.03 \% \mathrm{O}_{2}$ value was considered acceptable. Cells were incubated in this anaerobic chamber for $1 \mathrm{~h}$ and then removed from the anaerobic environment. Hence, neurobasal media were substituted and cultures placed in $95 \%$ air and $5 \% \mathrm{CO}_{2}$ conditions, for $3 \mathrm{~h}$ of reoxygenation. Cells of control group were treated identically except that they were not exposed to OGD/R.

\section{Cell Viability Evaluation}

Quantifications of neuronal viability were assessed by MTS method using Cell Titer One Solution Cell Proliferation Assay (Promega Corporation Madison, WI, USA) based on 3-(4,5dimethylthiazol-2-yl)-5-(3-carboxymethoxyphenil)-2-(4sulfophenyl)-2H-tetrazolium (MTS) (dilution 1:10). Viable cells with active metabolism convert MTT into formazan, detected by absorbance measurements at $490 \mathrm{~nm}$ in a BioTeek Elx800 microplate reader. Acridine Orange (AO) and Propidium Iodide (PI) double staining have been used to evaluate viable and dead cells in controls and exposed neurons. Images have been acquired through a fluorescent microscope combined with a Digital Color Camera.

\section{Isolation of RNA and qRT-PCR}

The total RNA, including microRNA (miRNA), from cells in cultures were extracted with Ribospin Kit (GenaAll) followed by Riboclear Plus Kit (GenaAll) to remove residual DNA according to the manufacturer's protocols.

Total mRNA transcription $(2 \mu \mathrm{g} / 20 \mu \mathrm{l})$ was performed using High Capacity cDNA Reverse Transcription Kit (Applied Biosystems) and reverse transcription for MicroRNA $(10 \mathrm{ng} / 15 \mu \mathrm{l})$ was performed using TaqMan MicroRNA Reverse Transcription Kit (Applied Biosystems).
The qPCR $20 \mu \mathrm{l} /$ reactions for miR-181a (assay ID: hsa-miR-181a) and C5aR (assay ID: Rn02134203_s1) were conducted in triplicate using TaqMan ${ }^{\circledR}$ MicroRNA Assay Kit and TaqMan ${ }^{\circledR}$ Gene Expression Assays protocol (Applied Biosystems), respectively, following the manufacturer's instructions. Reactions were performed using a Step One Plus Applied Biosystems thermocycler (Life Technologies) with the default protocol. Briefly, for each reaction 40 cycles of amplification with the following profile were performed: $95^{\circ} \mathrm{C}$ for $10 \mathrm{~min}$ for the first cycle, followed by 40 cycles of $95^{\circ} \mathrm{C}$ for $15 \mathrm{~s}$, and $60{ }^{\circ} \mathrm{C}$ for $1 \mathrm{~min}$.

Relative intensity of PCR-specific amplicons was calculated using the $2^{-\Delta \Delta \mathrm{Ct}}$ method (Livak and Schmittgen 2001). Beta-actin (assay ID: Rn00667869 m1) and U6 (assay ID: 001973) small nuclear RNA (snRNA) (Han et al. 2015) were used as internal control to normalize the level of each transcript.

\section{Fluo-4 NW Calcium Assay}

Neuronal cells, grown on 96-well plates, were exposed to $\mathrm{OGD} / \mathrm{R}$ and treated with $500 \mathrm{nM}$ of DF3016A; growth media were removed, and $100 \mu \mathrm{l}$ of the dye loading solution (F36206 Fluo-4 NW Calcium Assay Kit, Invitrogen) was added carefully to each well. Plates were incubated at $37^{\circ} \mathrm{C}$ for $30 \mathrm{~min}$ and then at room temperature for an additional $30 \mathrm{~min}$. Fluorescence was revealed at $516 \mathrm{~nm}$ with Victor 3 Model 1420-012 Multi-label Microplate Reader. Data were presented as the ratio between $\mathrm{Ca}^{++}$influx and neuronal viability.

\section{ELISAs}

Quantitative measurements of cellular proteins (C5a, TNF- $\alpha$, IL-1 $\beta$, and IL-6) in cell culture supernatants were determined by ELISA methods using Rat IL-6, Mouse TNF $\alpha$, Rat IL-1 $\beta$ PicoKine $^{\mathrm{TM}}$ ELISA Kits (Boster Biological Technology) and Rat C5a ELISA Kit (Elabscience Biotechnology Inc.) according to the manufacturer's instructions. All tests were performed in triplicate.

\section{Data Analysis}

Data are expressed as mean \pm standard error of mean (SE). Mean group differences were evaluated by one-way analysis of variance (ANOVA) followed by Bonferroni's post hoc test. $P$ values less than 0.05 were considered statistically significant. All statistical analyses were performed using SPSS 19.0 software. 


\section{Results}

\section{In Vitro Characterization}

In vitro pharmacological characterization showed that DF3016A did not inhibit spontaneous cell migration per se yet potently inhibited the $\mathrm{C} 5 \mathrm{a}$-induced human $\mathrm{PMN}$ migration with an $\mathrm{IC}_{50}$ of $50 \mathrm{nM}$ and cross-reactions with rat and mouse $\mathrm{C} 5 \mathrm{aR}\left(\mathrm{IC}_{50}=45 \mathrm{nM}\right.$ and $37 \mathrm{nM}$, respectively). The compound exhibited a high degree of selectivity with no effect on PMN migration induced by other leukocyte activators such as CXCL8, CXCL1, CCL3, fMLP, CXCL12, and on LPSinduced PGE2 accumulation up to $10 \mu \mathrm{M}$ concentration.

\section{In Vitro Selectivity}

DF3016A was tested in order to assess the off-target activities towards a panel of GPCRs, enzymes, ion channels, transporters, and nuclear receptors (44 targets in total, according to the SafetyScreen 44 assay provided by Eurofins Cerep). Radioligand binding assays were carried out at the test concentration of $10 \mu \mathrm{M}$ in triplicate. We found that DF3016A did not show any inhibition of the assayed receptors, confirming the high selectivity towards the $\mathrm{C} 5 \mathrm{aR}$.

\section{Brain Penetration in Rats}

With the aim of assessing the therapeutic potential of DF3016A in CNS disorders, brain penetration of the molecule was tested in SD rats after oral administration at $30 \mathrm{mg} / \mathrm{kg}$. At $2 \mathrm{~h}$ postdose $\left(T_{\max }\right)$, we found that the levels of DF3016A were $104,683 \mathrm{ng} / \mathrm{ml}$ in plasma and $4172 \mathrm{ng} / \mathrm{g}$ in brain, with a brain to plasma ratio of 0.04 . Once adjusted for the free plasma and brain fractions ( $0.7 \%$ and $7.7 \%$, respectively), this increases to an unbound brain to plasma ratio (Kpuu) of 0.44 (Table 1). This means that oral DF3016A is able to sufficiently penetrate the brain.

\section{DF3016A Evaluation on Neuronal Viability}

To evaluate the effects of DF3016A on neuronal viability we performed dose-response experiments with different DF3016A concentrations for $24 \mathrm{~h}$. Data were obtained using the MTS assay from three different cultures; neurons exhibited dose-dependent changes in cellular viability (Fig. 1a). From $10 \mathrm{nM}$ to $5 \mu \mathrm{M}$ of DF3016A concentration, no significant mortality was observed compared to the control. On the basis of these results, the $500 \mathrm{nM}$ concentration was chosen for performing the subsequent experiments, and cortical neurons were treated for 24,48 , and $72 \mathrm{~h}$ without significant viability changes (Fig. 1b).

\section{Cellular Viability After OGD-R Injury}

To examine the effect of DF3016A during OGD and at different time points of re-oxygenation, $500 \mathrm{nM}$ of DF3016A was added to the culture medium. As estimated by the MTS assay, the viability of OGD/R cultures was reduced by about $20 \%$ compared to the control. Following 3 to $48 \mathrm{~h}$ of reperfusion, the treatment with $500 \mathrm{nM}$ DF3016A significantly attenuated OGD/R-induced cell death (Fig. 2). As described, neuronal viability was also assessed using Acridine Orange/Ethidium Bromide (AO/ET) staining. Viable cells appear evenly green, in contrast to dead cells that appear as red spots due to chromatinic deposits. OGD/R exposure induced an increase in neuronal loss (Fig. 3c, d) while in ischemic neurons, treated with DF3016A, the neuronal death caused by OGD/R exposure was close to that of control (Fig. 3e, f).

\section{Effects of DF3016A Treatment on Neuronal Calcium Influx}

$\mathrm{C} 5 \mathrm{aR}$ has been suggested to also act as a modulator of $\mathrm{Ca}^{2+}$ influx via L-type voltage-gated $\mathrm{Ca}^{2+}$ channels (L-VGCCs) in neurons (Farkas et al. 2012). As shown in Fig. 4, OGD/R-UT exposure induced an abnormal $\mathrm{Ca}^{2+}$ influx $(P<0.001 \mathrm{vs}$ nonexposed cells) related to neuronal loss (shown in Fig. 2) probably due to excitotoxicity events. Notably, the 500-nM C5a antagonist treatment triggered a significant reduction of $\mathrm{Ca}^{2+}$ influx in OGD/R neurons $(P<0.001 \mathrm{OGD} / \mathrm{R}-\mathrm{DF}$ vs OGD/RUT cells).

\section{DF3016A as an Antagonist on C5a And C5aR Expression}

From the results obtained after OGD/R exposure, regarding the expression of $\mathrm{C} 5 \mathrm{aR}$ and $\mathrm{C} 5 \mathrm{a}$ protein release, we have observed a significant decrease of $\mathrm{C} 5 \mathrm{a}$ released protein (Fig. 5a), tightly related to the $\mathrm{C} 5 \mathrm{aR}$ over-expression (Fig. 5b). DF3016A treatment reverted C5aR gene expression to the control levels (Fig. 5b). Likewise, DF3016A restored C5a protein level to not significant values compared to control (Fig. 5a).

\section{DF3016A Effects on Pro-Inflammatory Cytokines}

Considering that $\mathrm{C} 5 \mathrm{aR}$ activation largely contributes to inflammatory responses in several diseases leading to neurodegenerative conditions (Choudhry et al. 2016; Yanamadala and Friedlander 2010), we analyzed the major pro-inflammatory cytokine release after $\mathrm{OGD} / \mathrm{R}$ exposure in neuronal cultures with and without 500-nM DF3016A treatment. ELISA analysis showed a significant upregulation of TNF- $\alpha$ (Fig. 6a) and IL-1 $\beta$ (Fig. $6 b$ ) during ischemic neuronal injury. The IL-6 release was higher in OGD/R, even if data were not significant 
Table 1 Concentrations of DF3016A in plasma and brain of rats following oral dosing $(30 \mathrm{mg} / \mathrm{kg})$

\begin{tabular}{llllll}
\hline DF3016A & & & & \\
\hline rPPB Fu & rBTB Fu & PK $(30 \mathrm{mg} / \mathrm{kg}, \mathrm{PO})$ & & \\
\cline { 3 - 6 } & & Plasma $C_{\max }(\mathrm{ng} / \mathrm{mL})$ & Brain $C_{\max }(\mathrm{ng} / \mathrm{g})$ & $\mathrm{Kp}$ & $\mathrm{Kpuu}$ \\
\hline $0.7 \%$ & $7.7 \%$ & $104,683 \pm 8867$ & $4172 \pm 323$ & 0.04 & 0.44 \\
\hline
\end{tabular}

The values of plasma and brain concentrations are the mean \pm S.D. $(n=3)$

rPPB rat plasma protein binding, rBTB rat brain tissue binding, Kp brain to plasma ratio, Kpuu unbound brain to plasma ratio
(Fig. 6c). The effect on IL-6 was surprising. We presume that our sublethal stimulation was unable to elicit enough IL-6 expression in cortical neurons. Indeed, recent data demonstrated that high IL-6 levels are released in dorsal root ganglion cultures with high satellite glial cell levels (80\%) and is stimulated by lipopolysaccharide release (Leisengang et al. 2018). $\mathrm{C} 5 \mathrm{aR}$ antagonist treatment lead to a restoration of control conditions of ischemic/hypoxic neurons (Fig. 6a, b).
Fig. 1 a Effect of different concentration of DF3016A on neuronal cortical cells. Values in the columns are means \pm SEM of three different cultures. The line + symbol shows the same data as a percentage of vitality. b Viability of neurons treated with $500 \mathrm{nM}$ of DF3016A for 24,48 , and $72 \mathrm{~h}$
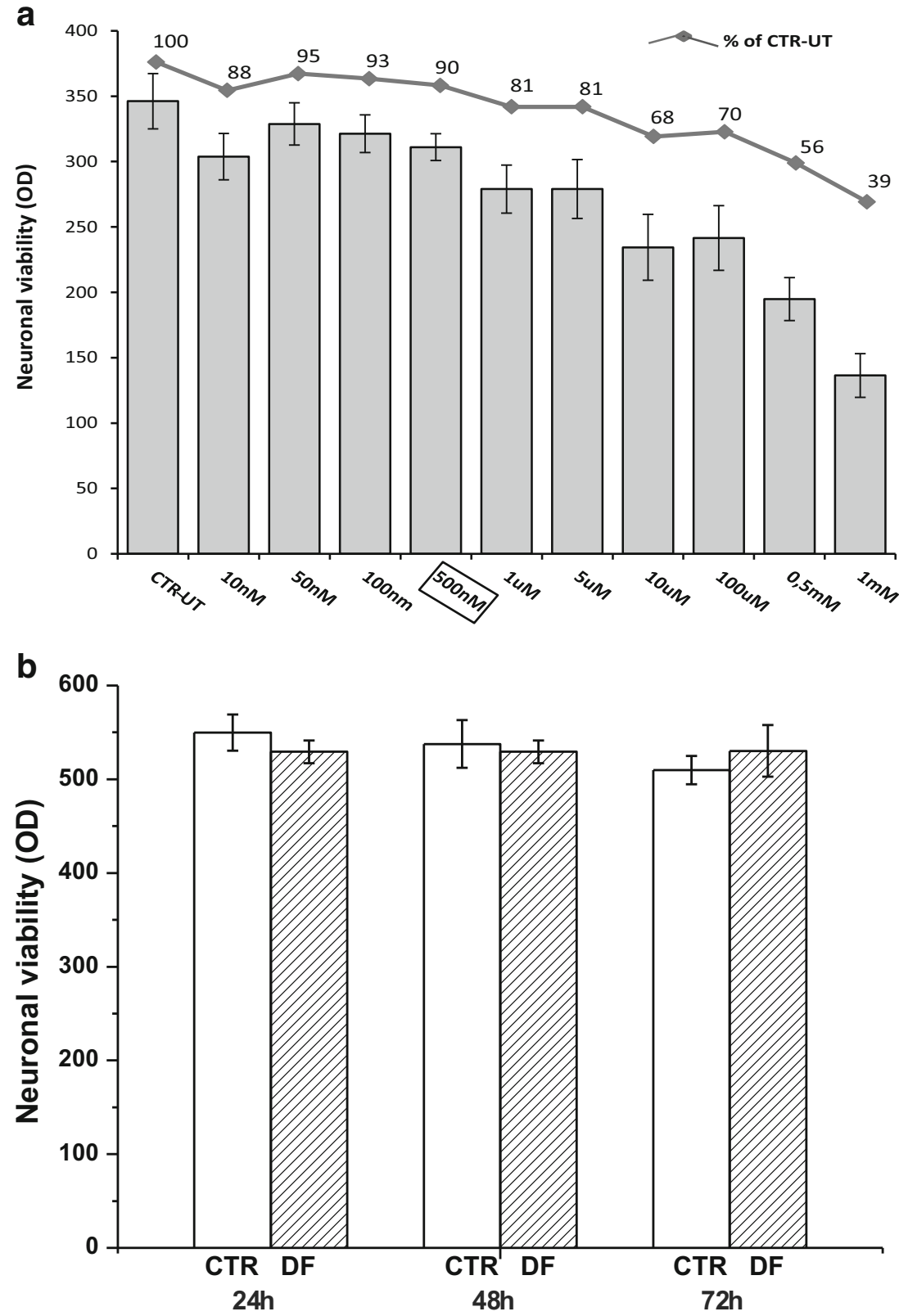


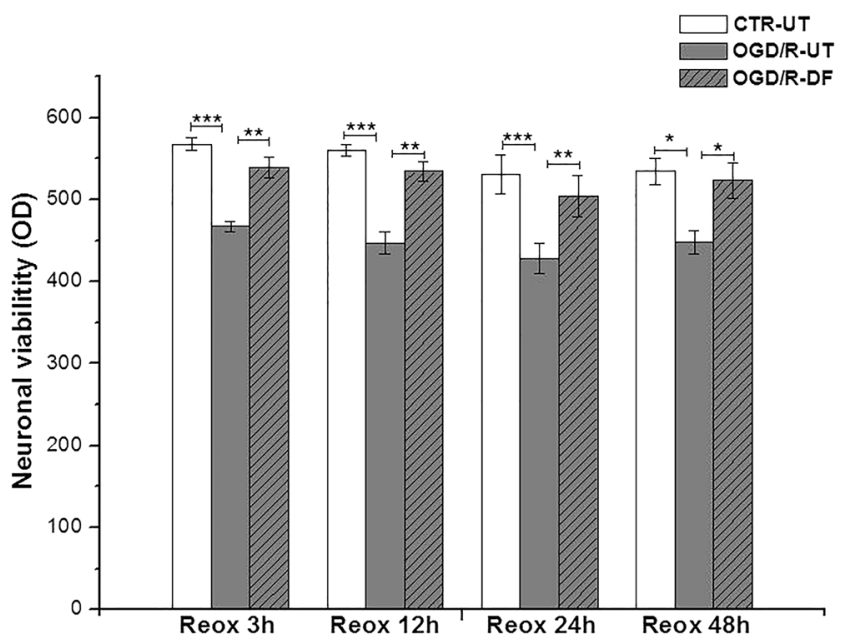

Fig. 2 Cortical neurons treated with DF3016A $500 \mathrm{nM}$ and exposed to OGD and different reoxygenation time points $(3,12,24,48 \mathrm{~h})$. Data are means \pm SEM of three different cultures. $* P<0.05, * * P<0.01$, $* * * P<0.001$ (Bonferroni's post hoc test). CTR-UT control-untreated, OGD/R-UT neurons exposed to OGD/R, CTR-DF control treated with $500 \mathrm{nM}$ DF3016A, OGD/R-DF neurons exposed to OGD/R and treated with $500 \mathrm{nM}$ DF3016A

\section{Effects of DF3016A on miR-181a Expression}

MicroRNAs, small non-coding RNA molecules, play an essential role in the regulation of gene expression through the degradation/inhibition of mRNA targets. In particular, miR181 a seems to be actively involved in the response to inflammatory stimuli (Xie et al. 2013). OGD/R induced a significant upregulation of miR-181 expression $(P<0.01$ vs non-exposed cells), but DF3016A treatment completely attenuated the miR-181a over-expression $(P<0.001$ OGD/R-DF vs OGD/ R-UT) (Fig. 7).

\section{Discussion}

Neuroinflammation can involve activation of the brain immune system in response to an inflammatory challenge (Alexander et al. 2008). It is characterized by cellular and molecular changes within the brain that involve many immunological mediators such as the complement system (Van Beek et al. 2003). Neuroinflammation and the subsequent neurodegenerative processes have clear clinical consequences (Paladini et al. 2015; Paladini et al. 2016; Fusco et al. 2017; Zis et al. 2017; Zis et al. 2017a; Varrassi et al. 2018) Uncontrolled complement activation can lead to excess tissue inflammation and damage; moreover, neuroinflammation induces sensitization and synaptic hyperactivity in the peripheral and central nervous system (Varrassi et al. 2015).

Here we evaluated the effects of DF3016A, a new molecule that acts as a selective C5aR antagonist. C5a is a crucial terminal component of the complement cascade supporting nociceptive sensitization and inflammation. The results reported here show that DF3016A is a potent and specific inhibitor of C5aR (IC50 in the nanomolar range) with a high selectivity based on a panel of GPCRs. Furthermore, DF3016A is characterized as an orally bioavailable $\mathrm{C} 5 \mathrm{aR}$ antagonist (rat bioavailability = $69 \%$, oral $t_{1 / 2}=6.1 \mathrm{~h}$ ) with good brain penetration $($ Kpuu $=0.44)$ upon oral administration. Based on this evidence, we further characterized the effects of the compound on primary rat cortical neurons exposed to sublethal $\mathrm{OGD} / \mathrm{R}$, an in vitro model of neuroinflammationrelated processes. Firstly, we showed that treatment with DF3016A for $24 \mathrm{~h}$ in the concentration range $10 \mathrm{nM}-$ $5 \mu \mathrm{M}$ did not affect neuronal viability and the toxic concentration of DF3016A (TC50 = dose that kills $50 \%$ of the cells) was between 0.5 and $1 \mathrm{mM}$. Additionally, a longer treatment for up to $72 \mathrm{~h}$ with $500 \mathrm{nM}$ DF3016A did not affect significantly neuronal viability. We then tested the effect of the drug using the OGD/R model that produces deficits in synaptic function, which has been widely used as an in vitro model to mimic the effects of ischemiareperfusion injury and neuroinflammation in neurodegenerative diseases. Our experimental protocol was based on the exposure of primary neuronal cultures to $1 \mathrm{~h}$ of OGD and $3 \mathrm{~h}$ of reoxygenation. The protocol also allowed us to study the early neuronal response, based on the finding of no significant differences in the viability of cultures kept in the reoxygenation state for up to $48 \mathrm{~h}$. This insult induces a mild degree of neuronal death and allows investigation of the functional activity of viable neurons. During ischemia, an excess of calcium influx is believed to be one of the first events triggering excitotoxic cell death (Mukherjee and Pasinetti 2001; Farkas et al. 1998). The increase in intracellular calcium level is an important element in the signal-transduction network activated after the binding of $\mathrm{C} 5 \mathrm{a}$ fragment complement to cell-surface receptors (Monk and Partridge 1993; Triantafilou et al. 2013). We observed that DF3016A treatment nullified the large increase of $\mathrm{Ca}^{2+}$ influx induced by $\mathrm{OGD} / \mathrm{R}$ and restored calcium concentrations to control levels. Previous work has demonstrated that the increased levels of released C5a in neuronal cultures exposed to OGD are tightly linked to apoptosis (Pavlovski et al. 2012). In the present study, we did not observe any increase in release of $\mathrm{C} 5$ a protein in $\mathrm{OGD} / \mathrm{R}$ neurons. On the contrary, C5aR gene expression was upregulated after OGD/R treatment. This upregulation is an interesting and may suggest that our OGD/R model induces an early upregulation of $\mathrm{C} 5 \mathrm{aR}$ expression, and subsequent binding of $\mathrm{C} 5 \mathrm{a}$ to its receptor, explaining the lower levels of $\mathrm{C} 5 \mathrm{a}$ protein observed. It is noteworthy that the complement pathway can be activated immediately after neuronal injury, and the increased receptor expression is one of the 
Fig. 3 Acridine Orange/Ethidium Bromide (AO/ET) staining for discrimination of live and dead cells. a, b represent control neurons; $\mathbf{c}, \mathbf{d}$ are neurons exposed to $\mathrm{OGD} / \mathrm{R} 3 \mathrm{~h}$; and $\mathbf{e}, \mathbf{f}$ are neurons treated with $500 \mathrm{nM}$ DF3016A and exposed to OGD/R $3 \mathrm{~h}$
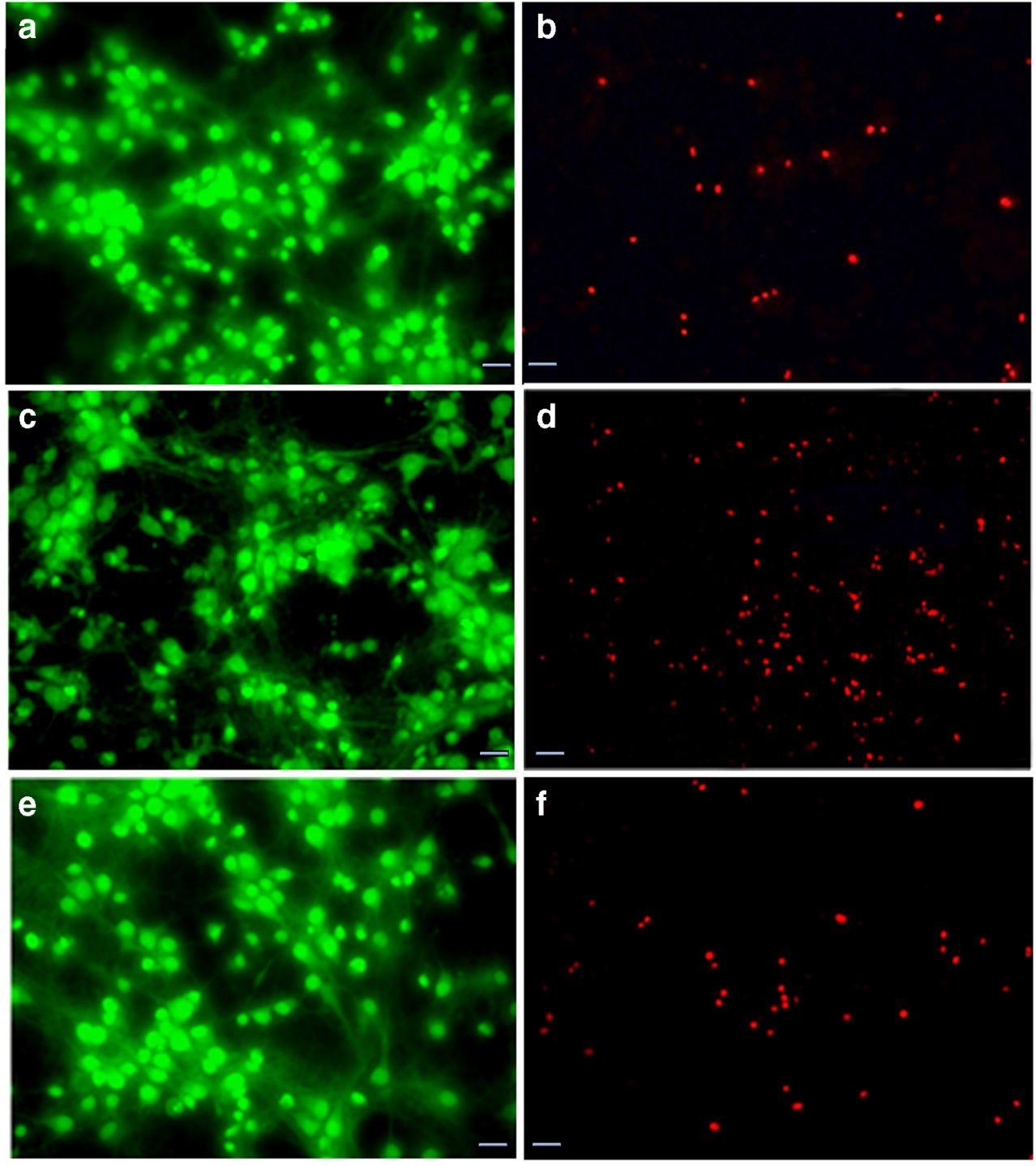

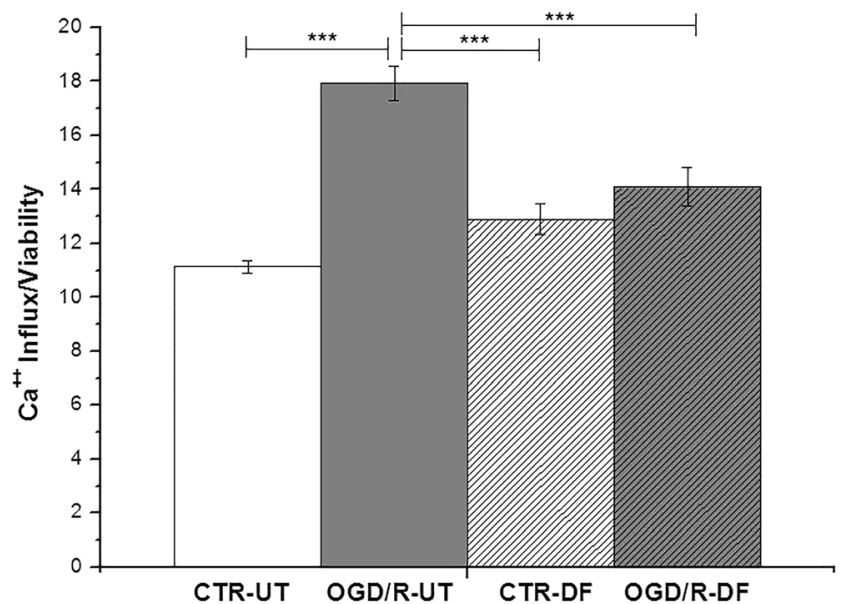

Fig. 4 Calcium influx measured in control and DF-treated cultures exposed to $\mathrm{OGD} / \mathrm{R}$ first steps in this response (Woodruff et al. 2010). Moreover, our results may not be in contrast to those previously observed after $12 \mathrm{~h}$ of OGD (Pavlovski et al. 2012), as the increase in C5a protein could be a subsequent process activated by more detrimental injuries, leading neuronal cells to apoptosis. Indeed, production of a proteolytic fragment of $\mathrm{C} 5 \mathrm{a}$ is a late event in the complement cascade, regulated by many complement-regulatory molecules which are subject to control by the expression of several receptors such as inflammatory mediators (Woodruff et al. 2010; Van Beek et al. 2000). However, DF3016A treatment restores the control situation, with the expression of $\mathrm{C} 5 \mathrm{a}$ maintaining the unchanged levels of the protein in OGD/R-treated neurons. As shown by different authors (Sayah et al. 1999; Song et al. 2018), C5a protein binding to its receptor can lead to the production of pro-inflammatory cytokines such as IL- $1 \beta$, TNF- $\alpha$, and IL-6 which in turn affect complement expression (Busch 


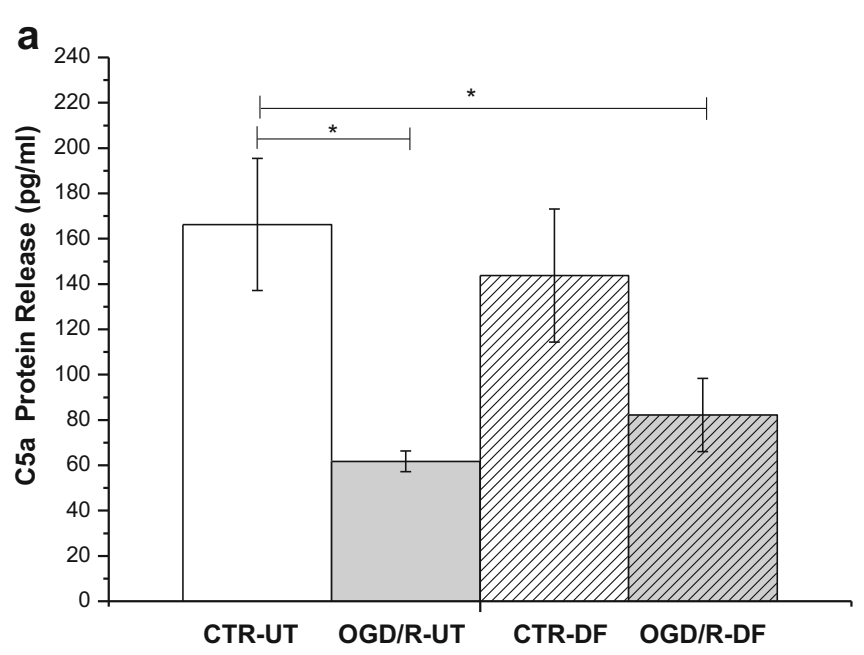

Fig. 5 a OGD/R-UT condition dramatically reduced the C5a protein level but induced a significant increase of C5aR gene expression. b DF3016A $\mathrm{C} 5 \mathrm{aR}$ antagonist notably reduced $\mathrm{C} 5 \mathrm{aR}$ transcription (mean \pm SEM six independent experiments). $* P<0.05, * * P<0.01, * * * P<0.000$

et al. 2013). In keeping with these pieces of evidence, in our experimental model, we observed overexpression of the major pro-inflammatory cytokines in OGD/R-exposed cultures. Remarkably, DF3016A treatment abolished the increase. The complex cytokine network in CNS is involved not only in the immune response but also in a variety of physiological and pathological processes (Szelényi 2001). Nevertheless, even though there are reports that low concentrations of cytokines can exhibit beneficial effects on neuronal viability and neurological function (Di Loreto et al. 2000; Vezzani and Viviani 2015), an injury-induced overexpression promotes neuronal death.

Increasing evidence supports a significant role for miRNAs in response to cerebral ischemia (Ouyang and Giffard 2013; Dharap et al. 2009). MiRNAs are small non-coding RNA molecules that control gene expression at the posttranscriptional level, and are abundantly expressed during

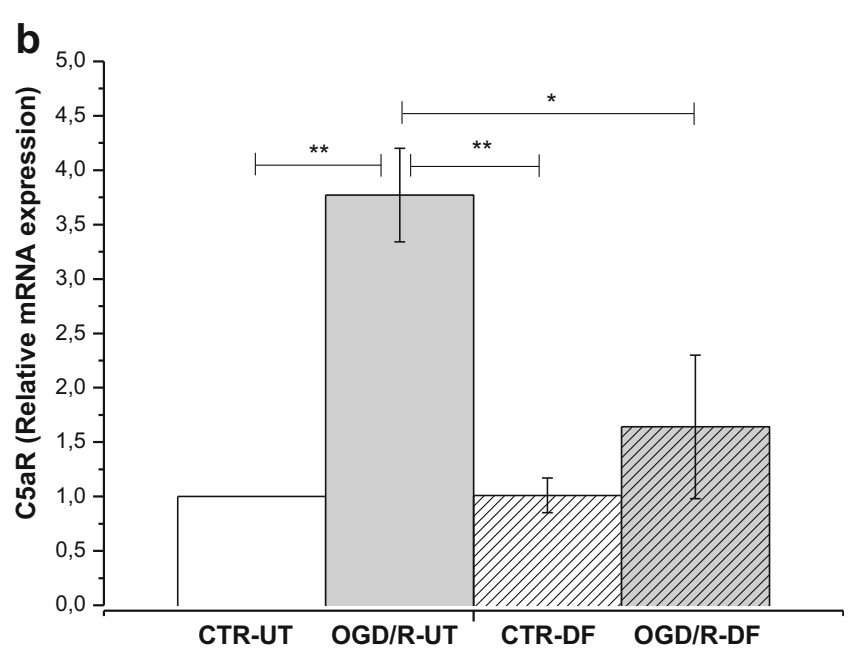

(Bonferroni's post hoc test). CTR/R-UT control-untreated, OGD/R-UT OGD/R exposed neurons, CTR/R-DF control treated with $500 \mathrm{nM}$ DF3016A, OGD/R-DF OGD/R exposed neurons treated with $500 \mathrm{nM}$ DF3016A

brain development and in the adult mammalian brain (Kos et al. 2016). MiRNAs target messenger RNAs (mRNAs). MiRNAs can induce mRNA degradation or the repression of the process of translation to modulate gene expression, and a single miRNA can bind and regulate several mRNA targets. The miR-181 family, especially miR-181a and miR-181b, are enriched in the brain (Miska et al. 2004), and their aberrant expression has been associated with brain diseases. The knockdown of miR-181a enhanced the production of proinflammatory cytokines (TNF- $\alpha$, IL-6, IL-1 $\beta$, IL-8) (Hutchison et al. 2013), and increased levels of the antiinflammatory cytokine IL-10 result from miR-181 over-expression (Murray 2005; de Vries 1995) in a murine stroke model. In a model of cerebral ischemia, the expression of miR-181 increases in the area where cell death occurs, whereas expression is lower in the penumbra zone where cells can survive (Ouyang et al. 2012). Altogether, these data indicate that miR-181 is involved in general transcriptional profiles of
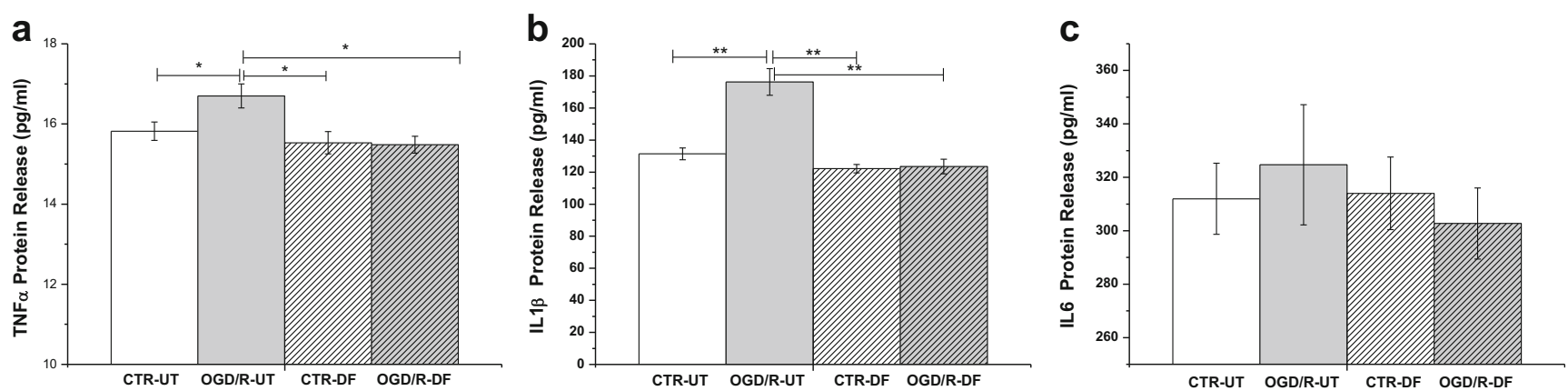

Fig. 6 Graph showing pro-inflammatory cytokine release after OGD/R exposure and DF3016A treatment (mean \pm SEM of four independent experiments; $* P<0.05, * * P<0.01$ ) (Bonferroni's post hoc test). CTR-
UT control-untreated, OGD/R-UT OGD/R exposed neurons, CTR-DF control treated with $500 \mathrm{nM}$ DF3016A, OGD/R-DF OGD/R exposed neurons treated with $500 \mathrm{nM}$ DF3016A 


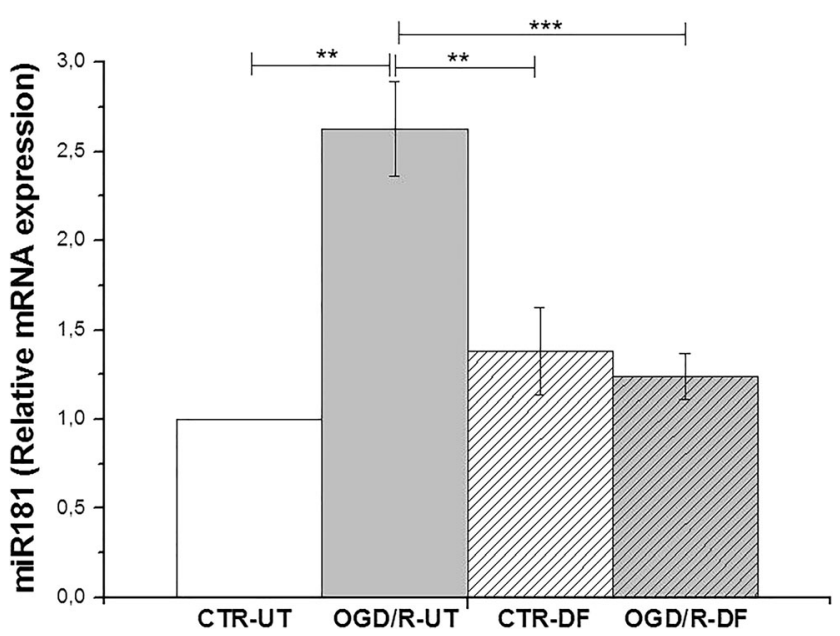

Fig. 7 Graph showing the miR-181a relative gene expression levels under OGD/R condition and DF3016A treatment. Data from four independent experiments (mean $\pm \mathrm{SEM}$ ). $* * P<0.01$, $* * * P<0.000$ (Bonferroni's post hoc test). CTR-UT control-untreated, OGD/R-UT OGD/R exposed neurons, CTR-DF control treated with $500 \mathrm{nM}$ DF3016A, OGD/R-DF OGD/R exposed neurons treated with $500 \mathrm{nM}$ DF3016A

cellular stress response and cellular survival-related changes. Therefore, we focused on the investigation of miR-181a in our model. Our data revealed increases in miR-181a expression after OGD/R exposure that could represent an early neuronal response to ischemic injury. DF3016A treatment completely abolished this over-expression, suggesting that this C5aR antagonist could affect immune-mediator expression also through interactions with transcriptional factors such as miR-181a. The overall profile of DF3016A made it an excellent candidate for additional in vitro and in vivo studies to assess the pharmacological effects of a C5aR antagonist with good brain penetration.

\section{Conclusion}

Altogether, these results support for the first time the hypothesis that DF3016A, a potent and selective C5aR inhibitor, might exhibit neuroprotective effects against neuroinflammatory processes induced by $\mathrm{OGD} / \mathrm{R}$ in primary cortical neurons. This could have important clinical consequences. Our experimental model allowed the investigation of CNS molecular and biological mechanisms in a controlled environment in vitro and on individual cell types. We did not study potential interactions with different cellular phenotypes in the brain. In conclusion, this study suggests that DF3016A might be a candidate molecule for a novel therapeutic approach to neuroinflammationrelated diseases. Further researches are in progress to evaluate the possible cellular and molecular mechanisms underlying the observed neuroprotection.
Acknowledgements The authors are indebted to Professor Anthony Dickenson for the critical review of the final manuscript.

Funding This work was supported by the Paolo Procacci Foundation (PPF) and Dompé Farmaceutici SpA funds.

\section{Compliance with Ethical Standards}

Conflicts of Interest Laura Brandolini, Gianluca Bianchini, and Marcello Allegretti are employees of Dompé Farmaceutici SpA, Italy. The company has interests in the development of $\mathrm{C} 5 \mathrm{aR}$ antagonists for the treatment of pain conditions. The other authors declare that they have no conflict of interest.

Ethical Approval All procedures performed in studies involving animals were in accordance with the ethical standards of the institution or practice where the studies were conducted.

Open Access This article is distributed under the terms of the Creative Commons Attribution 4.0 International License (http:// creativecommons.org/licenses/by/4.0/), which permits unrestricted use, distribution, and reproduction in any medium, provided you give appropriate credit to the original author(s) and the source, provide a link to the Creative Commons license, and indicate if changes were made.

\section{References}

Alawieh A, Elvington A, Zhu H, Yu J, Kindy MS, Atkinson C, Tomlinson S (2015) Modulation of post-stroke degenerative and regenerative processes and subacute protection by site-targeted inhibition of the alternative pathway of complement. J Neuroinflammation 12:247. https://doi.org/10.1186/s12974-0150464-8

Alexander JJ, Anderson AJ, Barnum SR, Stevens B, Tenner AJ (2008) The complement cascade: Yin-Yang in neuroinflammation - neuroprotection and -degeneration. J Neurochem 107(5):1169-1187. https://doi.org/10.1111/j.1471-4159.2008.05668.x

Astrup J, Siesjö BK, Symon L (1981) Thresholds in cerebral ischemiathe ischemic penumbra. Stroke 12(6):723-725

Badaut J, Hirt L, Price M, de Castro Ribeiro M, Magistretti PJ, Regli L (2005) Hypoxia/hypoglycemia preconditioning prevents the loss of functional electrical activity in organotypic slice cultures. Brain Res 1051(1-2):117-122

Barnum SR (2002) Complement in central nervous system inflammation. Immunol Res 26(1-3):7-13 Review

Bertini R, Allegretti M, Bizzarri C, Moriconi A, Locati M, Zampella G, Cervellera MN, Di Cioccio V, Cesta MC, Galliera E, Martinez FO, Di Bitondo R, Troiani G, Sabbatini V, D'Anniballe G, Anacardio R, Cutrin JC, Cavalieri B, Mainiero F, Strippoli R, Villa P, Di Girolamo M, Martin F, Gentile M, Santoni A, Corda D, Poli G, Mantovani A, Ghezzi P, Colotta F (2004) Noncompetitive allosteric inhibitors of the inflammatory chemokine receptors CXCR1 and CXCR2: prevention of reperfusion injury. Proc Natl Acad Sci U S A 101(32): 11791-11796

Bowes J, Brown AJ, Hamon J, Jarolimek W, Sridhar A, Waldron G, Whitebread S (2012) Reducing safety-related drug attrition: the use of in vitro pharmacological profiling. Nat Rev Drug Discov 11(12):909-922. https://doi.org/10.1038/nrd3845

Busch C, Girke G, Kohl B, Stoll C, Lemke M, Krasnici S, Ertel W, Silawal S, John T, Schulze-Tanzil G (2013) Complement gene 
expression is regulated by pro-inflammatory cytokines and the anaphylatoxin C3a in human tenocytes. Mol Immunol 53(4):363 373. https://doi.org/10.1016/j.molimm.2012.09.001

Carroll MC (1998) The role of complement and complement receptors in induction and regulation of immunity. Annu Rev Immunol 16:545568 Review

Choudhry N, Li K, Zhang T, Wu KY, Song Y, Farrar CA, Wang N, Liu CF, Peng Q, Wu W, Sacks SH, Zhou W (2016) The complement factor 5 a receptor 1 has a pathogenic role in chronic inflammation and renal fibrosis in a murine model of chronic pyelonephritis. Kidney Int 90(3):540-554

Davoust N, Jones J, Stahel PF, Ames RS, Barnum SR (1999) Receptor for the $\mathrm{C} 3 \mathrm{a}$ anaphylatoxin is expressed by neurons and glial cells. Glia 26:201-211

de Vries JE (1995) Immunosuppressive and anti-inflammatory properties of interleukin 10. Ann Med 27(5):537-541 Review

Dharap A, Bowen K, Place R, Li LC, Vemuganti R (2009) Transient focal ischemia induces extensive temporal changes in rat cerebral microRNAome. J Cereb Blood Flow Metab 29(4):675-687

Di Loreto S, Corvetti L, Maccarone R, Piancatelli D, Adorno D (2000) Interleukin 1-beta modulates the effects of hypoxia in neuronal culture. J Neuroimmunol 106(1-2):32-42

Farkas I, Baranyi L, Takahashi M, Fukuda A, Liposits Z, Yamamoto T, Okada H (1998) A neuronal C5a receptor and an associated apoptotic signal transduction pathway. J Physiol 507(Pt 3):679-687

Farkas I, Takahashi M, Fukuda A, Yamamoto N, Akatsu H, Baranyi L, Tateyama H, YamamotoT ON, Okada H (2003) Complement C5a receptor-mediated signaling may be involved in neurodegeneration in Alzheimer's disease. J Immunol 170:5764-5771

Farkas I, Varju P, Szabo E, Hrabovszky E, Okada N, Okada H, Liposits Z (2008) Estrogen enhances expression of the complement C5a receptor and the $\mathrm{C} 5 \mathrm{a}$-agonist evoked calcium influx in hormone secreting neurons of the hypothalamus. Neurochem Int 52(4-5):846-856

Farkas I, Sárvári M, Aller M, Okada N, Okada H, Likó I, Liposits Z (2012) Estrogen receptor $\alpha$ and $\beta$ differentially mediate C5aR agonist evoked $\mathrm{Ca}^{2+}$-influx in neurons through L-type voltage-gated $\mathrm{Ca}^{2+}$ channels. Neurochem Int 60(6):631-639. https://doi.org/10. 1016/j.neuint.2012.02.024

Fusco M, Skaper S, Coaccioli S, Paladini A, Varrassi G (2017) Degenerative joint diseases and neuroinflammation. Pain Pract 17: 522-532. https://doi.org/10.1111/papr.12551

Gasque P, Singhrao SK, Neal JW, Götze O, Morgan BP (1997) Expression of the receptor for complement C5a (CD88) is upregulated on reactive astrocytes, microglia, and endothelial cells in the inflamed human central nervous system. Am J Pathol 150(1): 31-41

Goldberg MP, Choi DW (1993) Combined oxygen and glucose deprivation in cortical cell culture: calcium-dependent and calciumindependent mechanisms of neuronal injury. J Neurosci 3(8): 3510-3524

Han Z, Ge X, Tan J, Chen F, Gao H, Lei P, Zhang J (2015) Establishment of lipofection protocol for efficient miR-21 transfection into cortical neurons in vitro. DNA Cell Biol 34(12):703-709. https://doi.org/10. 1089/dna.2015.2800

Hutchison ER, Kawamoto EM, Taub DD, Lal A, Abdelmohsen K, Zhang Y, Wood WH 3rd, Lehrmann E, Camandola S, Becker KG, Gorospe M, Mattson MP (2013) Evidence for miR-181 involvement in neuroinflammatory responses of astrocytes. Glia 61(7):1018-1028. https://doi.org/10.1002/glia.22483

Kawahara K, Yanoma J, Tanaka M, Nakajima T, Kosugi T (2004) Nitric oxide produced during ischemia is toxic but crucial to preconditioning-induced ischemic tolerance of neurons in culture. Neurochem Res 29(4):797-804

Kos A, Olde Loohuis N, Meinhardt J, van Bokhoven H, Kaplan BB, Martens GJ, Aschrafi A (2016) MicroRNA-181 promotes synaptogenesis and attenuates axonal outgrowth in cortical neurons. Cell
Mol Life Sci 73(18):3555-3567. https://doi.org/10.1007/s00018016-2179-0

Leisengang S, Ott D, Murgott J, Gerstberger R, Rummel C, Roth J (2018 Dec 1) Primary cultures from rat dorsal root ganglia: responses of neurons and glial cells to somatosensory or inflammatory stimulation. Neuroscience. 394:1-13. https://doi.org/10.1016/j. neuroscience.2018.10.018

Livak KJ, Schmittgen TD (2001) Analysis of relative gene expression data using real-time quantitative PCR and the 2(- delta delta $\mathrm{C}(\mathrm{T}))$ method. Methods 25:402-408

Mascagni P, Sabbatini V, Biordi L, Martinotti S, Allegretti M, Marullo A, Caselli G, Bertini R (2000) R- and S-isomers of nonsteroidal antiinflammatory drugs differentially regulate cytokine production. Eur Cytokine Netw 11(2):185-192

Miska EA, Alvarez-Saavedra E, Townsend M, Yoshii A, Sestan N, Rakic P, Constantine-Paton M, Horvitz HR (2004) Microarray analysis of microRNA expression in the developing mammalian brain. Genome Biol 5:R68

Monk PN, Partridge LJ (1993) Characterization of a complementfragment-C5a-stimulated calcium-influx mechanism in U937 monocytic cells. Biochem J 295(Pt 3):679-684

Moriconi A, Cunha TM, Souza GR, Lopes AH, Cunha FQ, Carneiro VL, Pinto LG, Brandolini L, Aramini A, Bizzarri C, Bianchini G, Beccari AR, Fanton M, Bruno A, Costantino G, Bertini R, Galliera E, Locati M, Ferreira SH, Teixeira MM, Allegretti M (2014) Targeting the minor pocket of C5aR for the rational design of an oral allosteric inhibitor for inflammatory and neuropathic pain relief. Proc Natl Acad Sci U S A 111:16937-16942

Mukherjee P, Pasinetti GM (2000) The role of complement anaphylatoxin $\mathrm{C} 5 \mathrm{a}$ in neurodegeneration: implications in Alzheimer's disease. J Neuroimmunol 105(2):124-130 Review

Mukherjee P, Pasinetti GM (2001) Complement anaphylatoxin C5a neuroprotects through mitogen-activated protein kinase-dependent inhibition of caspase 3. J Neurochem 77(1):43-49

Müller-Ladner U, Jones JL, Wetsel RA, Gay S, Raine CS, Barnum SR (1996) Enhanced expression of chemotactic receptors in multiple sclerosis lesions. J Neurol Sci 144(1-2):135-41

Murray PJ (2005) The primary mechanism of the IL-10-regulated antiinflammatory response is to selectively inhibit transcription. Proc Natl Acad Sci U S A 102(24):8686-8691

Narayanan SV, Perez-Pinzon MA (2017) Ischemic preconditioning treatment of astrocytes transfers ischemic tolerance to neurons. Cond Med 1(1):2-8

O'Barr SA, Caguioa J, Gruol D, Perkins G, Ember JA, Hugli T, Cooper NR (2001) Neuronal expression of a functional receptor for the C5a complement activation fragment. J Immunol 166(6):4154-4162

Ouyang YB, Giffard RG (2013) MicroRNAs regulate the chaperone network in cerebral ischemia. Transl Stroke Res 4(6):693-703

Ouyang YB, Lu Y, Yue S, Xu LJ, Xiong XX, White RE, Sun X, Giffard RG (2012) miR-181 regulates GRP78 and influences outcome from cerebral ischemia in vitro and in vivo. Neurobiol Dis 45(1):555563. https://doi.org/10.1016/j.nbd.2011.09.012

Paladini A, Fusco M, Coaccioli S, Skaper SD, Varrassi G (2015) Chronic pain in the elderly: the case for new therapeutic strategies. Pain Physician 18:E863-E876

Paladini A, Fusco M, Cenacchi T, Schievano C, Piroli A, Varrassi G (2016) Palmitoylethanolamide, a special food for medical purposes, in the treatment of chronic pain: a pooled data meta-analysis. Pain Physician 19:11-24

Pavlovski D, Thundyil J, Monk PN, Wetsel RA, Taylor SM, Woodruff TM (2012) Generation of complement component C5a by ischemic neurons promotes neuronal apoptosis. FASEB J 6(9):3680-3690. https://doi.org/10.1096/fj.11-202382

Quadros AU, Cunha TM (2016) C5a and pain development: an old molecule, a new target. Pharmacol Res 112:58-67

Sayah S, Ischenko AM, Zhakhov A, Bonnard AS, Fontaine M (1999) Expression of cytokines by human astrocytomas following stimulation by $\mathrm{C} 3 \mathrm{a}$ and $\mathrm{C} 5 \mathrm{a}$ anaphylatoxins: specific increase in interleukin-6 mRNA expression. J Neurochem 72(6):2426-2436 
Song WC, Sarrias MR, Lambris JD (2000) Complement and innate immunity. Immunopharmacology 49:187-198

Song Y, Wu KY, Wu W, Duan ZY, Gao YF, Zhang LD, Chong T, Garstka MA, Zhou W, Li K (2018) Epithelial C5aR1 signaling enhances uropathogenic Escherichia coli adhesion to human renal tubular epithelial cells. Front Immunol 9:949. https://doi.org/10.3389/ fimmu.2018.00949

Stevens B, Allen NJ, Vazquez LE, Howell GR, Christopherson KS, Nouri N, Micheva KD, Mehalow AK, Huberman AD, Stafford B, Sher A, Litke AM, Lambris JD, Smith SJ, John SW, Barres BA (2007) The classical complement cascade mediates CNS synapse elimination. Cell 131(6):1164-1178

Szelényi J (2001) Cytokines and the central nervous system. Brain Res Bull 54(4):329-338 Review

Triantafilou K, Hughes TR, Triantafilou M, Morgan BP (2013) The complement membrane attack complex triggers intracellular $\mathrm{Ca}^{2+}$ fluxes leading to NLRP3 inflammasome activation. J Cell Sci 126(Pt 13): 2903-2913. https://doi.org/10.1242/jcs. 124388

Van Beek J, Bernaudin M, Petit E, Gasque P, Nouvelot A, MacKenzie ET, Fontaine M (2000) Expression of receptors for complement anaphylatoxins $\mathrm{C} 3 \mathrm{a}$ and $\mathrm{C} 5 \mathrm{a}$ following permanent focal cerebral ischemia in the mouse. Exp Neurol 161(1):373-382

Van Beek J, Elward K, Gasque P (2003) Activation of complement in the central nervous system: roles in neurodegeneration and neuroprotection. Ann N Y Acad Sci 992:56-71 Review

Varrassi G, Fusco M, Coaccioli S, Paladini A (2015) Chronic pain and neurodegenerative processes in elderly people. Pain Pract 15(1):1-3. https://doi.org/10.1111/papr.12254

Varrassi G, Fusco M, Skaper SD, Battelli D, Zis P, Coaccioli S, Pace MC, Paladini A (2018) A pharmacological rationale to reduce the incidence of opioid induced tolerance and hyperalgesia: a review. Pain Ther 7:59-75. https://doi.org/10.1007/s40122-018-0094-9
Vezzani A, Viviani B (2015) Neuromodulatory properties of inflammatory cytokines and their impact on neuronal excitability. Neuropharmacology 96(Pt a):70-82. https://doi.org/10.1016/j. neuropharm.2014.10.027

Woodruff TM, Ager RR, Tenner AJ, Noakes PG, Taylor SM (2010) The role of the complement system and the activation fragment C5a in the central nervous system. NeuroMolecular Med 12(2):179-192. https://doi.org/10.1007/s12017-009-8085-y

Xie W, Li Z, Li M, Xu N, Zhang Y (2013) miR-181a and inflammation: miRNA homeostasis response to inflammatory stimuli in vivo. Biochem Biophys Res Commun 430(2):647-652. https://doi.org/ 10.1016/j.bbrc.2012.11.097

Yanamadala V, Friedlander RM (2010) Complement factors and their G protein-coupled receptors in neuroprotection and neurodegeneration. Trends Mol Med 16(2):69-76

Zhou J, Kim SR, Westlund BS, Sparrow JR (2009) Complement activation by bisretinoid constituents of RPE lipofuscin. Invest Ophthalmol Vis Sci 50(3):1392-1399. https://doi.org/10.1167/iovs. 08-2868

Zis P, Daskalaki A, Bountouni I, Sykioti P, Varrassi G, Paladini A (2017) Depression and chronic pain in the elderly: links and management challenges. Clin Interv Aging 12:709-720. https://doi.org/10.2147/ CIA.S113576

Zis P, Paladini A, Piroli A, McHugh PC, Varrassi G, Hadjivassiliou (2017a) Pain as first manifestation of paraneoplastic neuropathies: a systematic review and meta-analysis. Pain Ther 6:143-151. https://doi.org/10.1007/s40122-017-0076-3

Publisher's Note Springer Nature remains neutral with regard to jurisdictional claims in published maps and institutional affiliations. 